\title{
Sensitivity Degradation of ISUAL Instruments and Its Impact on Observations
}

\author{
Alfred Bing-Chih Chen ${ }^{1, *}$, Yen-Jung Wu ${ }^{1}$, Chih-Yu Chiang ${ }^{2}$, Yin-Chieh Huang ${ }^{2}$, Cheng-Ling Kuo ${ }^{2}$, \\ Han-Tzong Su ${ }^{2,3}$, Rue-Ron Hsu ${ }^{2,3}$, Stephen B. Mende ${ }^{4}$, Harald U. Frey ${ }^{4}$, Stewart E. Harris ${ }^{4}$, \\ Yukihiro Takahashi ${ }^{5}$, and Lou-Chuan Lee ${ }^{6}$ \\ ${ }^{1}$ Institute of Space, Astrophysical and Plasma Sciences, National Cheng Kung University, Tainan, Taiwan \\ ${ }^{2}$ Department of Physics, National Cheng Kung University, Tainan, Taiwan \\ ${ }^{3}$ Earth Dynamic System Research Center, National Cheng Kung University, Tainan, Taiwan \\ ${ }^{4}$ Space Sciences Laboratory, University of California, Berkeley, USA \\ ${ }^{5}$ Department of Cosmosciences, Hokkaido University, Sapporo, Japan \\ ${ }^{6}$ Institute of Space Science, National Central University, Jhongli, Taiwan
}

Received 2 September 2010, accepted 20 June 2011

\begin{abstract}
In the past 6 years, the ISUAL payload onboard the Taiwanese FORMOSAT-2 satellite has successfully carried out the primary mission of performing a global survey of transient luminous events (TLE) and lightning activities. The observation data have been used to construct the first global distribution map of TLEs and to infer their occurrence rates. To register dim TLE emissions at night, ISUAL employs electron-multiplying devices like a photomultiplier, multi-anode array, and microchannel plate to intensify the photons emitted by transient events. These devices, however, will degrade gradually with age. The degradation rate and the performance change were monitored through periodic calibration observations and are investigated carefully in order to achieve precise photometry and accurate statistics. The annual degradation rates up to $14 \%$ were identified for some of the sensor elements. This paper presents the variations of instrument efficiencies and overall detection capabilities, before and after applying a gain-adjustment to compensate for sensor degradation. The resulting stable trend of the ISUAL trigger and lightning rates suggests that the bias from instrument degradation and gain adjustments is minimal. This point is also supported by the near constant sprite and halo detection rates deduced from different statistical temporal intervals. Hence, the anomalies in the ISUAL elve detection rate for $2008 \sim 2009$ likely are due to the El Niño and Southern Oscillation (ENSO) events. Forecast based on the ISUAL performance trend also indicates that the ISUAL sensors have sufficient sensitivity margins to operate efficiently until the end of 2013 , or even beyond.
\end{abstract}

Key words: Transient luminous events (TLEs), Lightning, Atmospheric electricity, Imager of Sprites and Upper Atmospheric Lightnings (ISUAL), Space instrument

Citation:Chen, A.B., Y.J.Wu, C.Y.Chiang, Y.C.Huang, C.L.Kuo, H.T.Su, R.R.Hsu, S.B.Mende, H.U.Frey, S.E.Harris, Y.Takahashi, and L.C.Lee, 2012 Sensitivity degradation of ISUAL instruments and its impact on observations. Terr. Atmos. Ocean. Sci., 23, 71-83, doi: 10.3319/TAO.2011.06.20.01(AA)

\section{INTRODUCTION}

A sprite, which is a brief flash occurring above the cloudtop of thunderstorms, and is one type of transient luminous events (TLEs), was first accidently discovered in 1989 (Franz et al. 1990). Subsequent observations, mainly from the ground, were conducted to explore the nature of this new phenomenon. In the process, several additional

\footnotetext{
* Corresponding author

E-mail:alfred@phys.ncku.edu.tw
}

types of TLEs including elve, blue jet, sprite halo, and gigantic jet were soon identified. Observational methods other than conventional optical ground observation have also been used to investigate their physical characteristics. For example, ELF waveform recording and triangulation by the Schumann Resonance method has been used to study the characteristics of TLEs' parent lightning, especially the charge moment change and the polarity (Huang et al. 1999; Sato and Fukunishi 2003; Cummer 2006). Space observation was first analyzed by Boeck et al. $(1995,1998)$, 
followed by man-operated observation onboard the tragic space shuttle mission STS-107 (Yair et al. 2004), and a nadir observation from the International Space Station (ISS, Blanc et al. 2004). Space observation is able to carry out global observations and overcome geographical limitations, especially for oceanic regions. However, due to the necessarily brief nature of space shuttle missions, they are not suitable for carrying out a long-term survey to investigate the global occurrence and the occurrence rate of TLEs. Therefore, the satellite mission ISUAL, Imager of Sprites and Upper Atmospheric Lightnings, was proposed and installed onboard the Taiwanese FORMOSAT-2 satellite as the major scientific payload. Detailed features of this mission were given in Chern et al. (2003). Through the efforts of an international team consisting of National Cheng Kung University (Taiwan), UC Berkeley (USA), and Tohoku University (Japan), and the National Space Organization (NSPO, Taiwan), FORMOSAT-2 was successfully built and launched on 21 May 2004 from Vandenberg Air Force Base, CA, USA. Serving as the first science mission dedicated to the study of TLEs, ISUAL successfully obtained not only the global distribution of TLEs (Chen et al. 2008; Lee et al. 2010), its major scientific goal, but also facilitated many new findings. An up-to-date publication list from this mission can be found on the ISUAL website (http://sprite. phys.ncku.edu.tw).

To capture the dim transient light emitted from TLEs, the ISUAL sensors were equipped with several electron multiplying devices such as micro-channel plates and photomultiplier tubes. These devices are driven by high voltage power supplies to accelerate and to multiply the collected electrons; inevitably their sensitivities will degrade with use. Compared with conventional semiconductor detectors used in most space missions, the degradation of the electron multiplying devices driven by high voltage power supplies is expected to be significant. Therefore, without a careful assessment of this degradation, a proper assessment of the payload performance and a correct photometry can not be achieved. We follow similar calibrations and performance evaluation practices that were used in many previous spacecraft missions (Boccippio et al. 2002; Mach et al. 2007; Massey 2010; Walker et al. 2010). Over the past several years, special calibration observations were conducted periodically to monitor the sensitivity changes. In this paper, the sensitivity degradation of the ISUAL sensors and the effects of the rises in high voltage to counter the degradation are reported. The impact of sensitivity degradation on the transient detection is also discussed. A forecast based on the calibration observations indicates that ISUAL is capable of successfully operating into the first phase of the extended mission (2009 2013) without difficulty. The calibration observations, methods of data reduction, as well as the degradation characteristics, and the extended life analysis of individual sensors are described in section 2 . The scientific impact of degradation and the effective gain change are discussed in section 3 , and the conclusions are summarized in section 4 .

\section{OBSERVATIONS AND DATA REDUCTION}

ISUAL consists of three sensors including an intensified CCD imager (iCCD hereafter) that captured the transient appearances of TLE or lightning flashes, a spectrophotometer (SP hereafter) that recorded light variations within the field of view at 6 bands simultaneously, and an array photometer (AP hereafter) that obtained the light curve at different vertical heights in blue and red channels. Chern et al. (2003) or the ISUAL website are to be referred to for detailed specifications of the ISUAL sensors.

In most of the satellite missions, known celestial sources are often used for the sensor calibrations. However for the ISUAL sensors, the moonlight is too strong and may cause permanent damage to the electron multiplying devices, even at low gain settings. Constant celestial sources, other than the Sun and Moon, are too dim and hard to be discerned in the light curves recorded by the ISUAL wide-field nonimaging detectors (photomultiplier tubes or array photometers). Hence this leaves us only with the option of using the built-in blinking LEDs as the standard light source, in place of conventional celestial objects (Kiefer 1995).

The ISUAL calibrators that were pre-installed inside the ISUAL sensors before launch are tiny light-emitting diodes (LEDs). A LED is a semiconductor device and is widely used in space missions as a light source for optocouplers (Lischka 1994; Reed 2002). The degradation of LEDs in a space environment has been well studied (Reed 2002 and references therein). The major degradation of a LED in space is caused by a displacement damage dose (DDD). Taking the depth-dose curve (ISO 15856, 2010) and the thickness of the aluminum shielding into account, the total dose that the ISUAL LED suffered in space during a 5 -year mission lifetime is less than $5 \mathrm{krad}$, and this dose is insufficient to cause a significant degradation (Lischka et al. 1994). Furthermore, these LEDs are turned on for only a few seconds every month for the purpose of calibration only. In general, a LED's age with operation time is defined as the time that a LED is on and forward biased. The cumulative operation time of LEDs is less than one hour in 6 years of ISUAL operation, and is far less than the typical aging period of a few thousand hours. Therefore, the aging factor due to ISUAL operation can be discounted. Another important factor that can affect the performance of LED is ambient temperature. We always turn on LEDs for calibration runs in high latitude areas ( $\sim 55$ degrees in the South or North). Inspecting the historic records of the temperatures inside the sensor housing reveals a variation less than 5 degrees centigrade. This implies that the performance change of LEDs due to temperature variation is negligible (Figs. 5 
and 7 of Schubert 2006). Therefore, the assumption that the emission brightness of LEDs installed in the ISUAL payload is nearly constant during the mission is reasonable.

To monitor the performance of the ISUAL sensors, a special calibration run is scheduled nearly every month, except for the first few months of the ISUAL mission, through measuring the built-in quick-blinking LED calibrators. To avoid light pollution from the Earth's surface, which mainly are city lights from metropolitan areas or moonlight reflections from clouds, ISUAL was programmed to point toward the dark space in the new moon phase during the calibration runs. Figure 1 shows samples of the calibration readings for two of the ISUAL SP and AP sensor units. Points connected by lines in the panels (a) (e) of Fig. 2 represent the observed amplitudes at the same gain setting. Due to the sensitivity degradation of the electron-multiplying devices, a gradual decrease in amplitude is clearly observed across all the channels shown in Fig. 2. Thus the high voltage setting for the sensor units must be raised to balance this degradation, or the blinking LEDs' amplitudes may become too faint to be identified. To evaluate the consistency of the settings in the calibration procedures, after the high voltage was changed, observations with two different settings were carried out in adjacent orbits. To this point, we have applied four high voltage raises for the ISUAL sensors since their launch. A careful in-lab calibration was done at the Space Science Laboratory, UC Berkeley and Tohoku University, Japan before the launch of the ISUAL. With calibration reports that noted the gain and applied voltage relation, we can easily convert the measured counts into scientific units using the voltage setting adopted for the observations. In this paper, calibration data collected from 7 July 2004, the first observation of ISUAL, to June 2009 was used for the analysis.

\subsection{Spectrophotometer}

A wide field (20 degrees by 5 degrees) spectrophotometer, consisting of 6 photomultiplier tubes (PMT) covering the wave bands from ultraviolet to red visible light (Table 1), acts as a fast-light collector with a sampling rate of $10 \mathrm{kHz}$ and the ISUAL event initiator. When the light variation at selected channels exceeds pre-set levels, a trigger signal is generated and sent simultaneously to all sensors. The trigger flag also causes the data in the circular buffers to be transferred to the Auxiliary Electronic Package (AEP). Eventually, the ISUAL data are downloaded to the Mission Control Center when FORMOSAT-2 flies over the ground station in Taiwan. Therefore, degradation of the SP will not only affect the derived brightness of the recorded TLEs, but also decrease the TLE detection efficiency and the global statistics of TLEs.

As described in the previous section, calibrations during the new moon were conducted periodically using the quick-blinking LED calibrators as shown in Fig. 1. To obtain precise amplitudes, we separate the measured data points into a bright group for data with counts exceeding the mean of all the data points, and a dark group for the rest. The mean and standard deviation $(\sigma)$ of each group are calculated respectively. The data points beyond mean plus or minus $3 \sigma$ are rejected and the mean and standard deviation are re-calculated for the remaining data points. This process iterates recursively until all data points fall within $3 \sigma$ of the mean. The amplitude of the calibrator is defined as the difference between the mean of the bright and dark groups after this $3 \sigma$ rejection. The emission band of the LED calibrators is mainly red, and the emitted photons are almost completely blocked by the far-UV filter for the SP channel 1 with a passing band of 150 to $280 \mathrm{~nm}$. This causes the number (a)

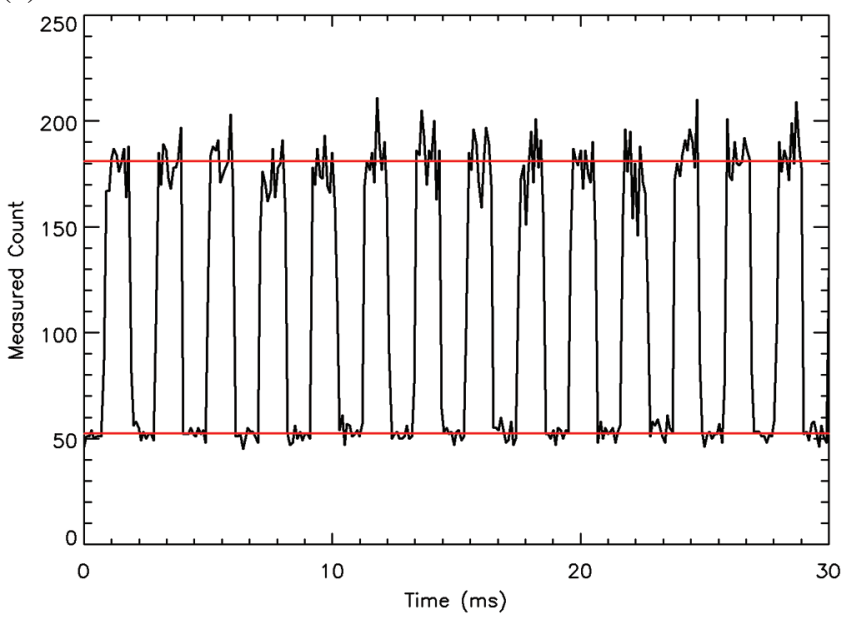

(b)

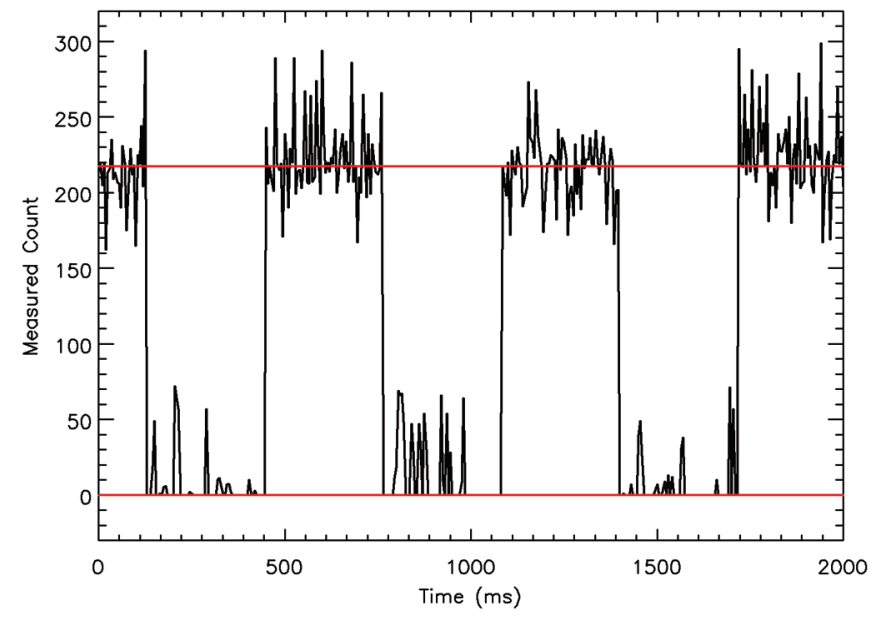

Fig. 1. A quick-blinking LED installed inside SP (a) and AP (b); the solid-red lines represent the average level where the LED is on and off (except zero as the ground level of AP calibrator). 
(a) Channel 2

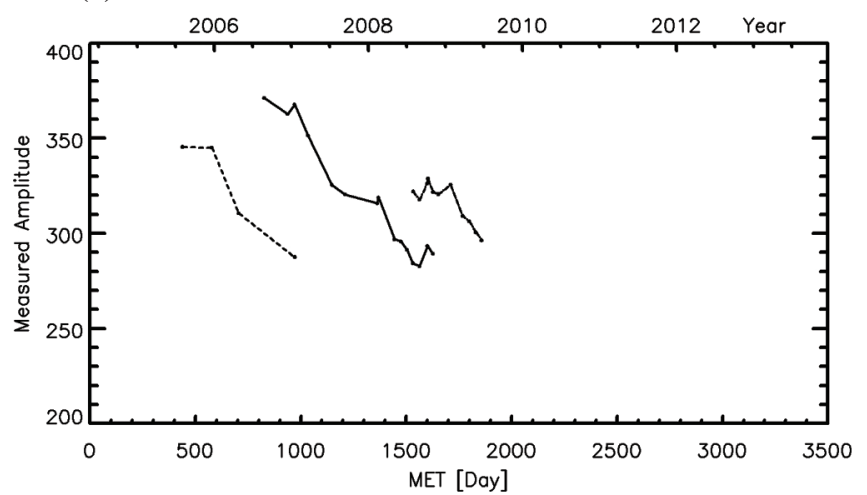

(c) Channel 4

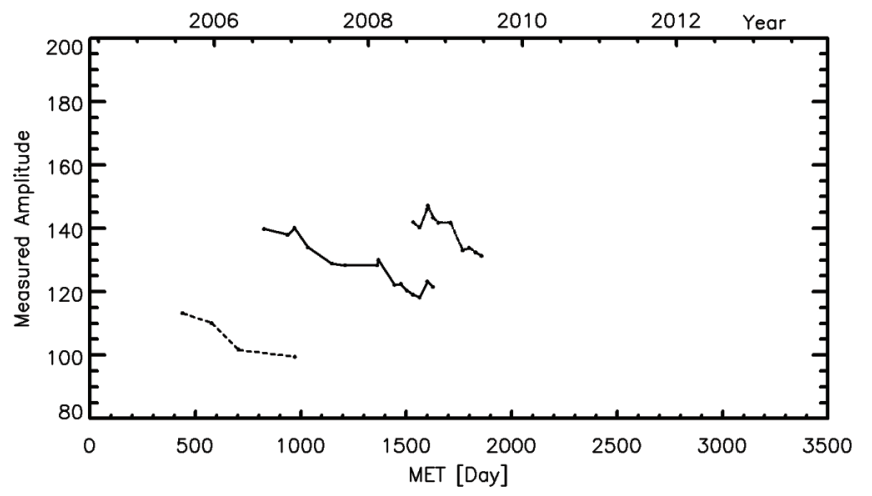

(e) Channel 6

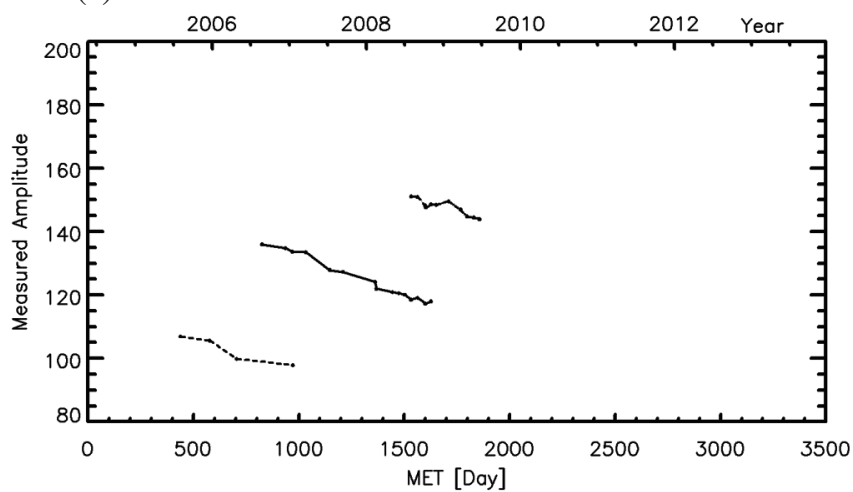

(b) Channel 3

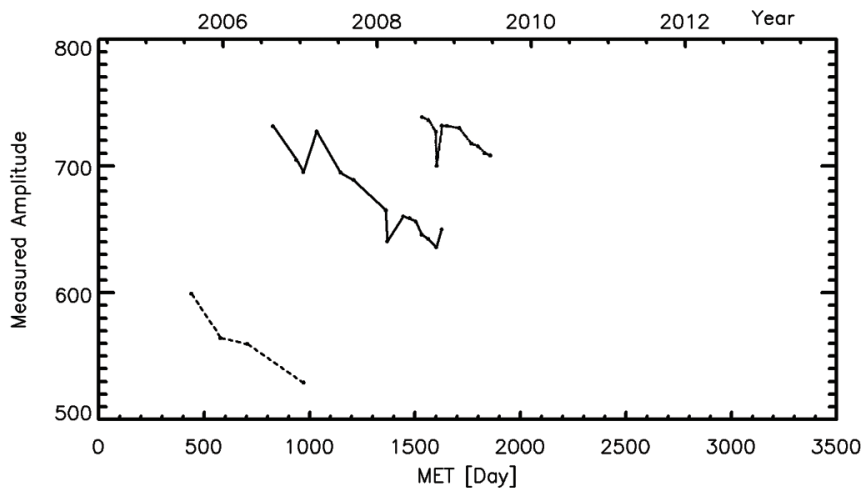

(d) Channel 5

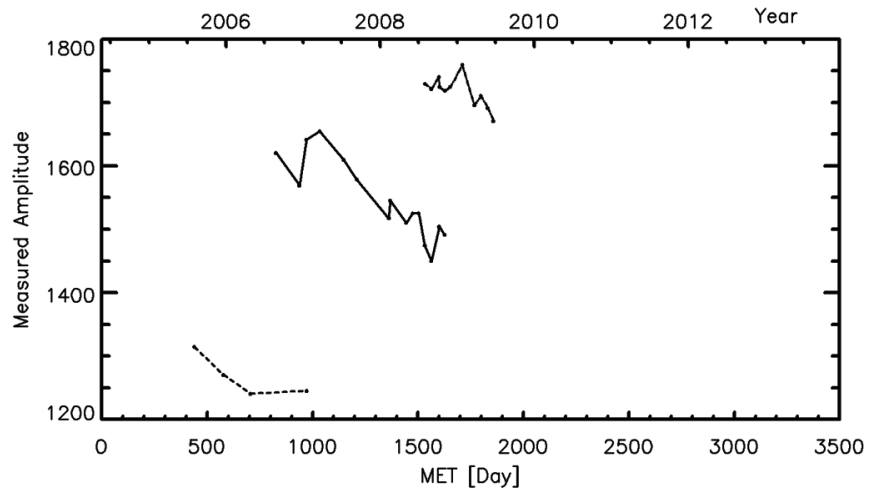

(f) Relative Gain Change

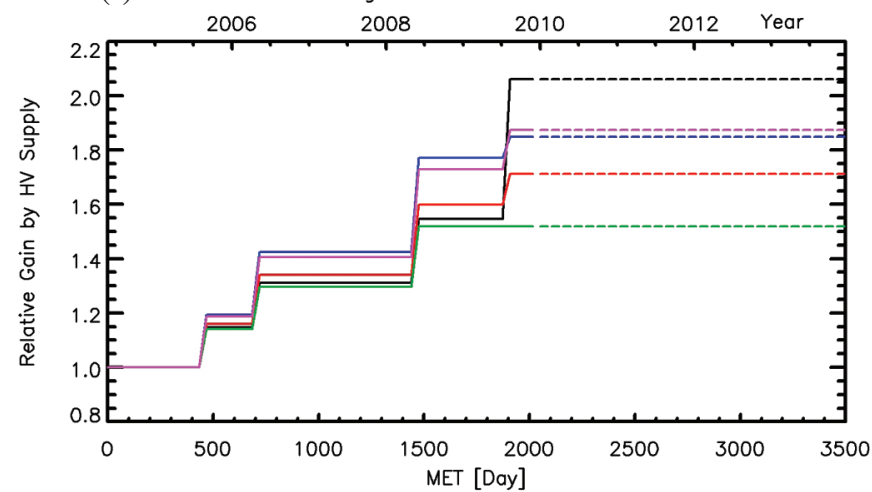

Fig. 2. (a) (e) Recorded raw amplitudes of SP channels except channel 1, which are taken under different high voltage settings with the applied gains not yet normalized. (f) Relative gain change that is controlled by supplied change. MET (Mission Elapsed Time) which is set to zero at the moment of liftoff and counted forward in normal time and used as a timing unit (Black, red, blue, green, and purple lines represent SP channel 2 to 6 , respectively).

Table 1. Characteristics of the SP channels and settings of the applied high voltage before and after four adjustments.

\begin{tabular}{|c|c|c|c|c|c|c|c|}
\hline $\begin{array}{c}\text { Date of } \\
\text { adjustment }\end{array}$ & $\begin{array}{c}\text { Center } \\
\text { wavelength } \\
(\mathbf{n m})\end{array}$ & $\begin{array}{c}\text { Band width } \\
\text { at } 50 \% \\
(\mathbf{n m})\end{array}$ & $2004 / 07 / 04$ & 2005/08/09 & $2006 / 05 / 06$ & $2008 / 05 / 13$ & 2009/07/15 \\
\hline MET (day) & & & 45 & 446 & 716 & 1454 & 1882 \\
\hline $\mathrm{HV}_{\mathrm{SP} \# 1}$ & 220 & 140 & $1650 \mathrm{~V}$ & $1670 \mathrm{~V}$ & $1690 \mathrm{~V}$ & $1715 \mathrm{~V}$ & $1745 \mathrm{~V}$ \\
\hline $\mathrm{HV}_{\mathrm{SP} \# 2}$ & 337 & 5.6 & $1425 \mathrm{~V}$ & $1445 \mathrm{~V}$ & $1465 \mathrm{~V}$ & $1490 \mathrm{~V}$ & $1535 \mathrm{~V}$ \\
\hline $\mathrm{HV}_{\mathrm{SP} \# 3}$ & 391.4 & 4.2 & $1375 \mathrm{~V}$ & $1395 \mathrm{~V}$ & $1415 \mathrm{~V}$ & $1440 \mathrm{~V}$ & $1450 \mathrm{~V}$ \\
\hline $\mathrm{HV}_{\mathrm{SP} \# 4}$ & 687 & 126.7 & $1050 \mathrm{~V}$ & $1070 \mathrm{~V}$ & $1090 \mathrm{~V}$ & $1115 \mathrm{~V}$ & $1120 \mathrm{~V}$ \\
\hline $\mathrm{HV}_{\mathrm{SP} H 5}$ & 779 & 7.9 & $1475 \mathrm{~V}$ & $1495 \mathrm{~V}$ & $1515 \mathrm{~V}$ & $1540 \mathrm{~V}$ & $1540 \mathrm{~V}$ \\
\hline $\mathrm{HV}_{\mathrm{SP} \# 6}$ & 317.6 & 148.2 & $1200 \mathrm{~V}$ & $1220 \mathrm{~V}$ & $1240 \mathrm{~V}$ & $1265 \mathrm{~V}$ & $1275 \mathrm{~V}$ \\
\hline
\end{tabular}


of the collected photons in the channel 1 to be extremely low, and hence the signal-to-noise ratio of the amplitude is not sufficient for further analysis.

The pre-flight calibration data was used to convert amplitudes obtained under different high voltage settings into meaningful scientific units. To simplify calculations, Mission Elapsed Time (MET or $t$ ) which is set to zero at the moment of liftoff and counts forward in normal time is used as a timing unit. Samples of the recorded raw amplitudes for SP channels $2 \sim 5$ are presented in Figs. $2 \mathrm{a} \sim$ e. The SP sensitivity decrease can be compensated through raising the supplied high voltage. However this compensation will also accelerate the degradation. Over the past few years, we have changed the gain setting four times since their launch, and the high voltage settings and corresponding periods are listed in Table 1. The relative gain change controlled only by the supplied high voltage is also displayed, Fig. $2 \mathrm{f}$. Taking this relative gain change into account, the amplitudes are all normalized to the remaining efficiency which is defined as $100 \%$ at $\mathrm{MET}=0$. The remaining derived efficiencies of SP channels are displayed in Fig. 3f and the degradation can be identified. We simply fit the $\operatorname{MET}(t)$ and the remaining (a) Channel 2

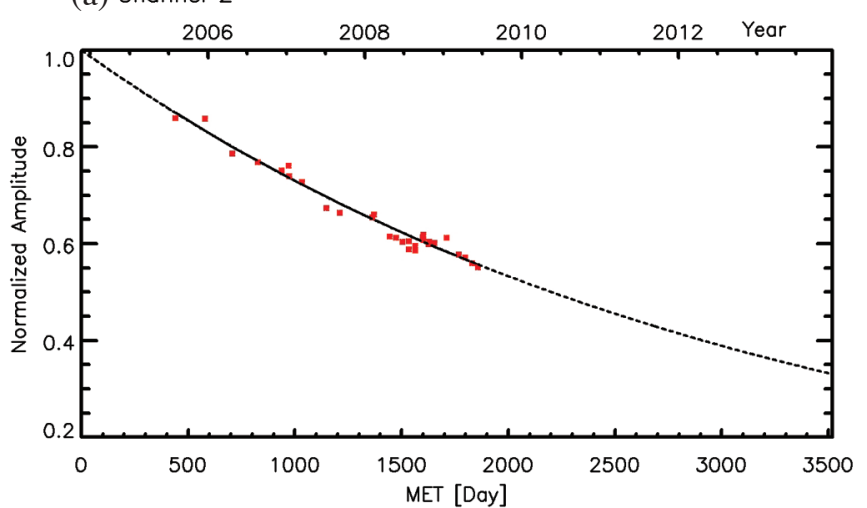

(c) Channel 4

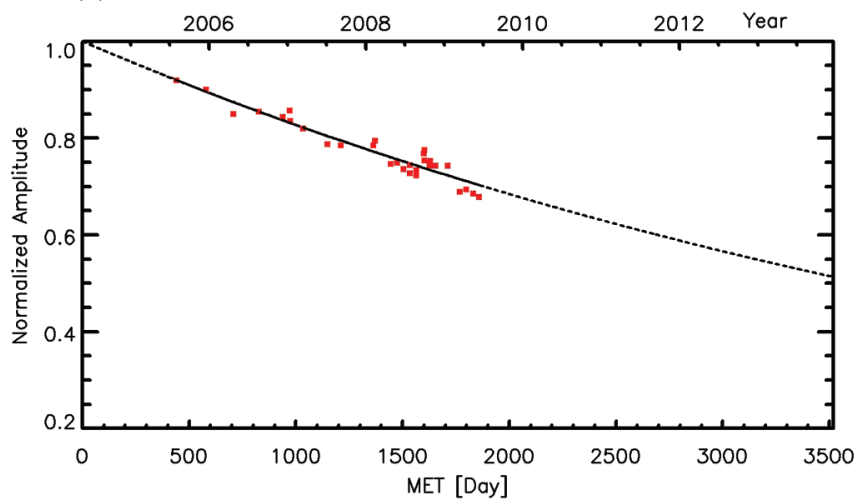

(e) Channel 6

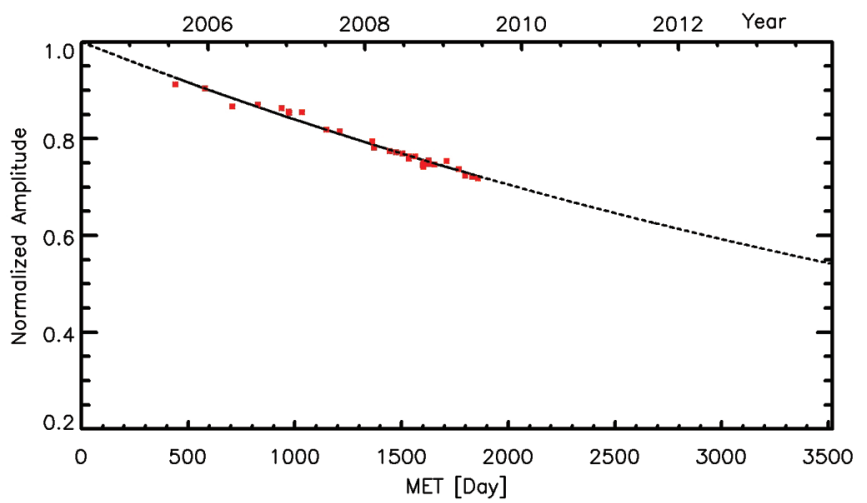

(b) Channel 3

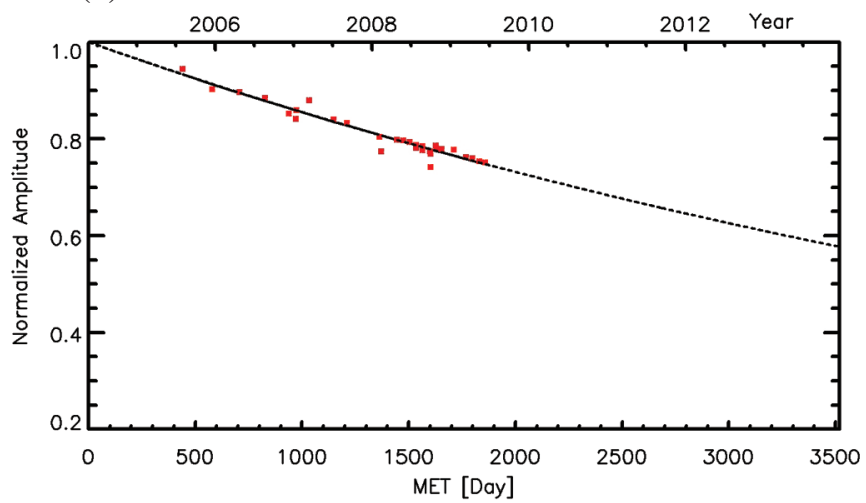

(d) Channel 5

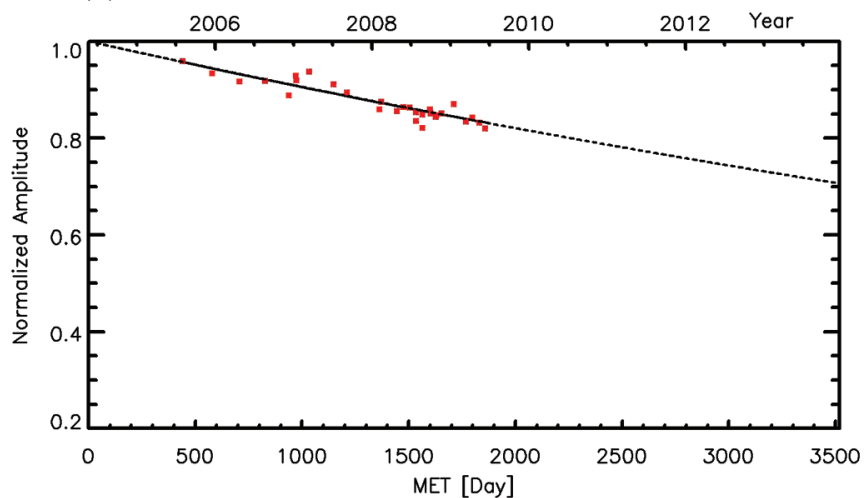

(f) Remaining Efficiency Change

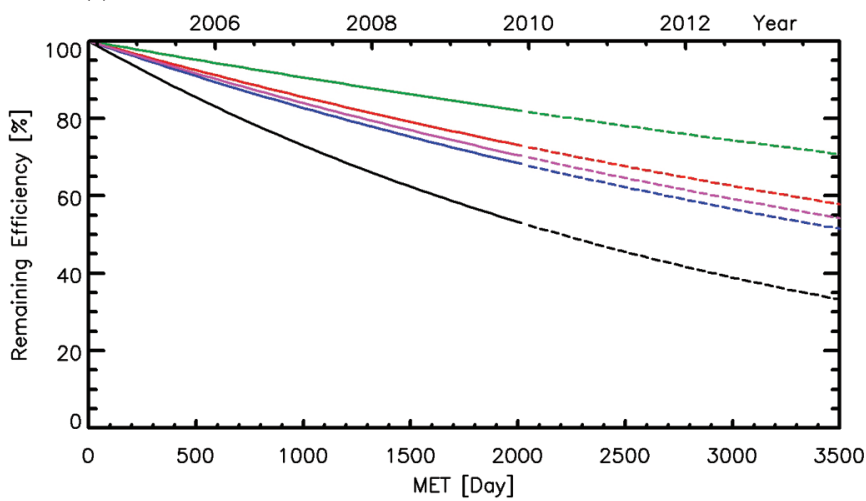

Fig. 3. (a) (e) Normalized amplitudes or the remaining efficientcy of the SP channels, showing a clear degradation with time. Exponential-decaying forms are used to fit the normalized amplitudes and the the best results are shown in the solid lines. (f) The forecast for the remaining efficiency of SP channels based on the degradation calculation (black, red, blue, green, and purple lines represent SP channel 2 to 6, respectively). 
efficiency $(r)$ with an exponential-decaying function:

$r=e^{-a_{i} t}$

where $a_{i}$ is the decay coefficient for the channel $i$. The best result is shown in Table 2 and Figs. $3 \mathrm{a} \sim \mathrm{e}$, and a forecast trend of SP channels is demonstrated in Fig. 3f. We can easily find that Channel 2 of SP, the worst channel, deteriorates at $14.4 \%$ per year, and only $40 \%$ efficiency remains at the end of 2010. We did our best to maintain the effective gain, which is the product of the remaining efficiency and the relative gain, near a constant. The effective gain change is shown in Fig. 4. But without long-term monitoring information, it is very hard to infer the degradation precisely during the mission. Therefore after the calibration data was collected, we found that channel 2 was under-adjusted and the other channels were over adjusted. But we can still conclude that the effective gain changes remained within approximately $100 \% \pm 20 \%$ from Fig. 4 . The impact of the effective gain change will be discussed in section 3 .

Since the relation of count to flux conversion under different supplied high voltages has been well established in the laboratory, this degradation must be taken into account to derive the correct photometry of the TLEs or lightning

Table 2. The derived degradations constants for the SP channels.

\begin{tabular}{cccc}
\hline Channel & $\begin{array}{c}\text { Center } \\
\text { wavelength }(\mathbf{n m})\end{array}$ & $\boldsymbol{a}\left(\times \mathbf{1 0}^{-4}\right)$ & $\begin{array}{c}\text { Annual } \\
\text { degradation }\end{array}$ \\
\hline 1 & 220 & (low S/N ratio, see text) \\
2 & 337 & 4.265 & $14.4 \%$ \\
3 & 391.4 & 2.235 & $7.8 \%$ \\
4 & 687 & 2.914 & $10.1 \%$ \\
5 & 779 & 1.492 & $5.3 \%$ \\
6 & 317.6 & 2.498 & $8.7 \%$ \\
\hline
\end{tabular}

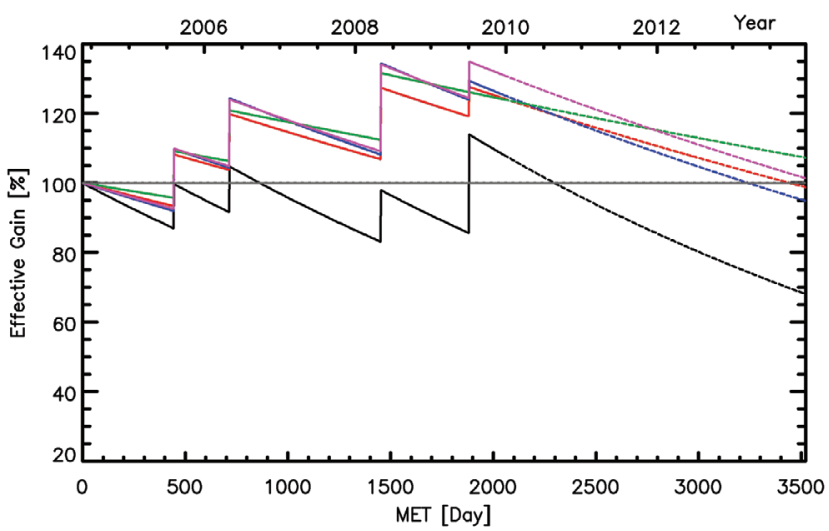

Fig. 4. Variation of the effective gain for the SP channels, where the effective gain is defined as the product of the effective gain (Fig. 2f) and the degradation (Fig. 3f). Black, red, blue, green, and purple lines represent SP channel 2 to 6 , respectively. obtained by SP. The deviation on the photometry caused by the average degradation for the first two years (Frey et al. 2005; Kuo et al. 2005, 2007; Mende et al. 2005; Liu et al. 2006 ) is found to be less than $15 \%$. This deviation level is comparable to the sources of the other noise such as readout noise and background variation caused by the moonlight reflection from the cloud-top or city light, and was neglected in those papers. But further studies must consider this degradation rates to derive correct $\mathrm{SP}$ photon fluxes.

\subsection{Array Photometer}

The use of an array photometer (AP) for the TLE research was first demonstrated by Fukunishi et al. (1996) during ground TLE observations. The deployment of an AP with two bands (blue: $360-470 \mathrm{~nm}$, red: $633-751 \mathrm{~nm}$ ) in space provides an excellent opportunity to explore the rapid change in TLE brightness at different altitudes with a combined field of view of 20 degrees by 3.6 degrees with a spatial resolution of $\sim 14 \mathrm{~km}$ near the Earth limb (Chern et al. 2003). Using the ISUAL AP data, several important results have been published in the past (Adachi et al. 2006, 2008; Kuo et al. 2009). The core component of the ISUAL AP consists of two high-voltage-powering multi-anode photomultipliers, with a function to multiply photoelectric-effect electrons generated by the dim luminosity of the TLEs. We use a similar technique for SP degradation analysis to monitor and calculate the sensitivity change of the AP channels. The only difference between SP and AP calibration is that an additional bias is applied to SP, so the average count of the SP calibrator at the "off" state is easy to identify. Without this offset, we simply take zero as the ground level of AP calibrator, and calculate only data points above the mean count. Amplitudes of light variation generated by the calibrator at blue channels are, however, too small to be detected because the power emitted by LEDs mostly centers at the red end $(>600 \mathrm{~nm})$ of the visible light, and the signal-to-noise ratio of the measured flux becomes very low behind a blue filter ( $360-470 \mathrm{~nm}$ ) of the array photometer. Therefore, we only evaluate the performance change of the red module and assume that the degradation patterns of blue module are similar, since the detecting units and the applied high voltage for both modules are identical, except one fitted with a blue mask and another one fitted with a red filter. The result of a best fit is shown in Table 3, and the best and worst two channels are plotted in Fig. 5 for comparison. We can estimate that the current remaining efficiency of AP channels is still higher than $80 \%$ relative to that on the MET 0 . The annual degradation rate is generally less than $4 \%$ for all the channels.

\subsection{Intensified CCD Imager}

An intensified CCD imager was used to record the 
Table 3. Derived degradation constants for the AP red channels.

\begin{tabular}{cccccc}
\hline $\mathbf{C h}$ & $\boldsymbol{a}\left(\times \mathbf{1 0}^{-5}\right)$ & $\begin{array}{c}\text { Annual } \\
\text { degradation }\end{array}$ & $\mathbf{C h}$ & $\boldsymbol{a}\left(\times \mathbf{1 0} \mathbf{5}^{-5}\right)$ & $\begin{array}{c}\text { Annual } \\
\text { degradation }\end{array}$ \\
\hline 1 & 9.910 & $3.55 \%$ & 9 & 6.313 & $2.28 \%$ \\
2 & 8.422 & $3.03 \%$ & 10 & 7.856 & $2.83 \%$ \\
3 & 10.506 & $3.76 \%$ & 11 & 6.649 & $2.40 \%$ \\
4 & 9.403 & $3.37 \%$ & 12 & 6.967 & $2.51 \%$ \\
5 & 9.392 & $3.37 \%$ & 13 & 5.697 & $2.06 \%$ \\
6 & 8.751 & $3.14 \%$ & 14 & 6.855 & $2.47 \%$ \\
7 & 9.229 & $3.31 \%$ & 15 & 6.374 & $2.30 \%$ \\
8 & 7.713 & $2.78 \%$ & 16 & 4.764 & $1.72 \%$ \\
\hline
\end{tabular}

(a)

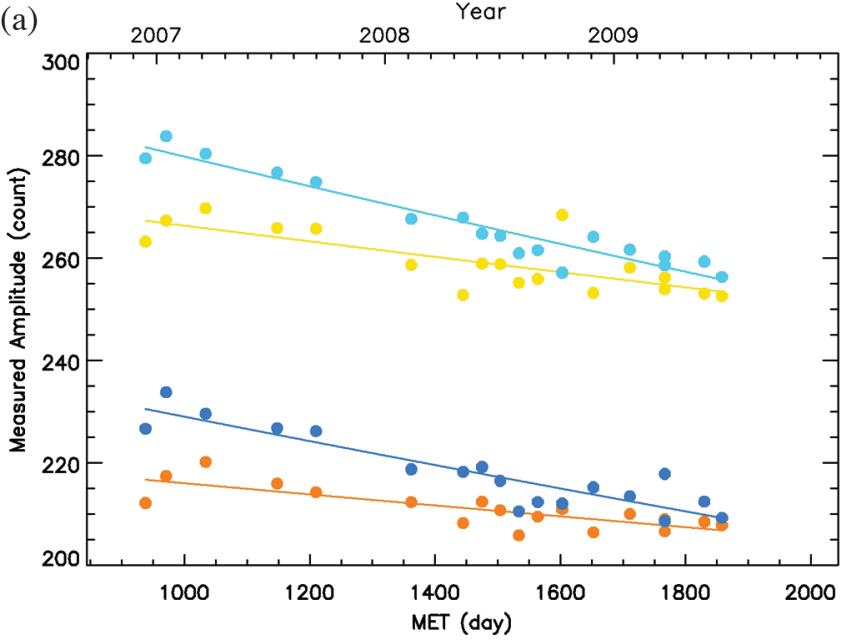

(b)

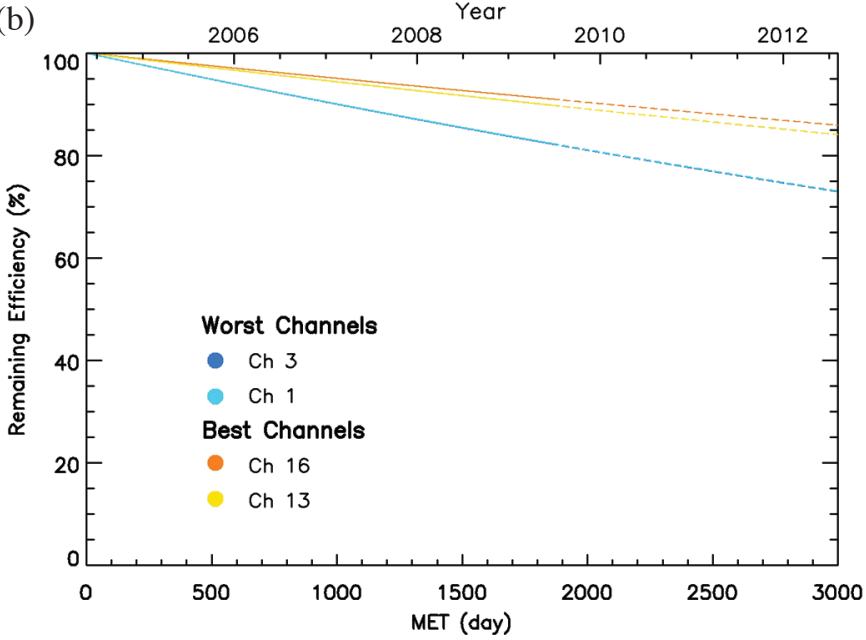

Fig. 5. (a) Measured amplitudes of the best and worst two AP red channels. The solid lines represent the best fits with the exponential-decaying form. (b) The forecast trending of AP remaining sensitivity.

morphology of the TLEs. To intensify the dim light emitted by TLEs, a micro-channel plate (MCP) multiplies the photoelectric electrons with a gain of $10^{5} \sim 10^{7}$. Although a similar LED was installed to be used for the monitoring of the degradation as for the other ISUAL sensors, the light from this small LED is still too dim even running the MCP under the highest safe high voltage setting. Hence, we cannot monitor the deterioration of the MCP using the built-in LED calibrator.

Another important iCCD component that will deteriorate with time is the phosphor. The electrons multiplied by the MCP are converted into visible light at a phosphor screen and then are registered by the CCD. The principle of this process is similar to the formation of images on a conventional television screen. Unfortunately, a phosphor screen will whiten after being used for an extended period. A consequence of the phosphor aging is the background count in the recorded images will increase gradually, diminishing the available dynamic range of the detector.

Airglows are dim emissions of atmospheric species induced by various processes in the upper atmosphere; examples such as the recombination of ions with electrons after they were photoionized by the solar radiations during daytime and chemiluminescence from oxygen and nitrogen reacting with hydroxyl molecules between 85 to a few hundred kilometer altitudes (Huang et al. 2010; Rajesh et al. 2009). Airglow observation is another scientific goal of the ISUAL mission (Chern et al. 2003). To capture the faint airglow emissions, the iCCD of ISUAL has to be operated with a relatively long exposure time, typically 1 second per frame, comparing with the short exposure time of 29 milliseconds for the TLE survey. Therefore, the performance change of iCCD under both the short and the long exposure settings also is an important issue for an ISUAL experiment.

To learn of the deterioration of the phosphor screen under different exposure time settings, we selected some images collected during the new moon phase with short and long exposure times (29 and $1000 \mathrm{~ms}$ respectively) and calculated their background counts. A typical background change trend of the ISUAL iCCD imager is demonstrated 
in Fig. 6. The result clearly shows that the background increases at a rate of 8 counts per year for a short exposure time. But the background increases dramatically at almost 1 count per day for a long exposure time and for the higher gain setting, which is typically used for the airglow observations. This is a severe warning that the ISUAL may not be able to carry out airglow observations after another two or three years because the high background has pushed the operation range of the iCCD imager too close to the edge of the linearity range, whose count is 2800 . The increase in the image background, however, will not affect the TLE survey because it can be easily removed after a sky background subtraction.

\subsection{Lifetime Prediction}

The design lifetime of the ISUAL was set to be at least 5 years. The sensitivity of the ISUAL sensors inevitably will degrade. The ISUAL operation team has tried to counter the degradation through increasing the gain via raising the high voltages, and to maintain a uniform detection capability throughout the mission. However, the ceiling of the high voltage setting will eventually limit the mission life, even if no major electronic or mechanical problems are encountered in the future. These ceiling voltages are incorporated as the important design parameters and are listed in the operation handbook. Taking the maximum voltage and current settings of all the ISUAL sensors into account (Table 4), the usable gain is greater than four. The remaining efficiencies of the major ISUAL sensors are given in Figs. $3 \mathrm{f}$ and $5 \mathrm{~b}$. Therefore, when taking a more conservative stand, ISUAL should be able to operate efficiently until the end of 2013 $(\mathrm{MET}=3512)$, at least 3 more years into the extended mission, without major difficulties.

\section{IMPACT OF THE EFFECTIVE GAIN CHANGE}

The TLE detection ability of ISUAL depends mainly on its effective gain, which is the product of the remaining efficiency multiplied by the relative gain determining by the high voltages that are supplied to the PMTs of the SP. It is natural to expect that the recorded lightning or TLEs will decrease gradually if the gain settings remain adjusted after an extended period. Hence we have to increase the relative (a)

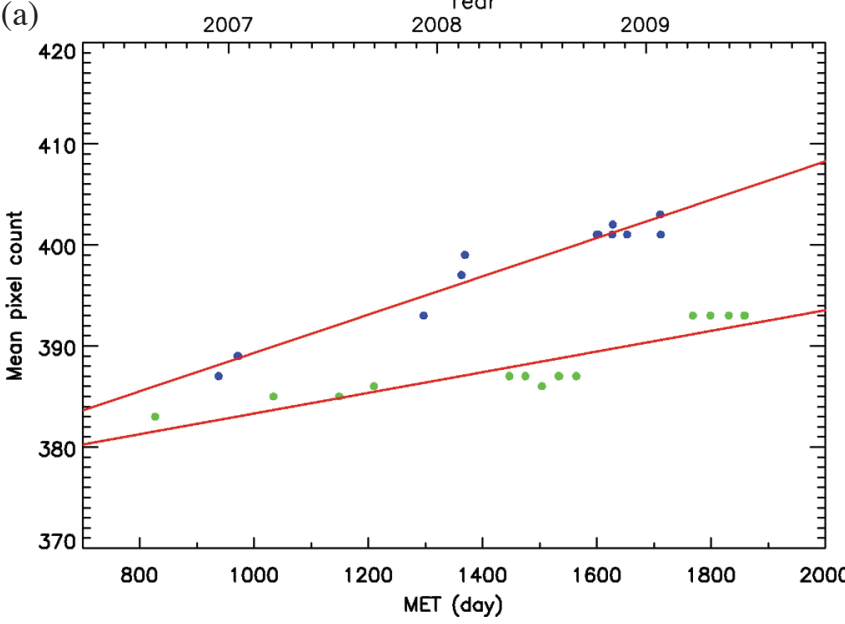

(b)

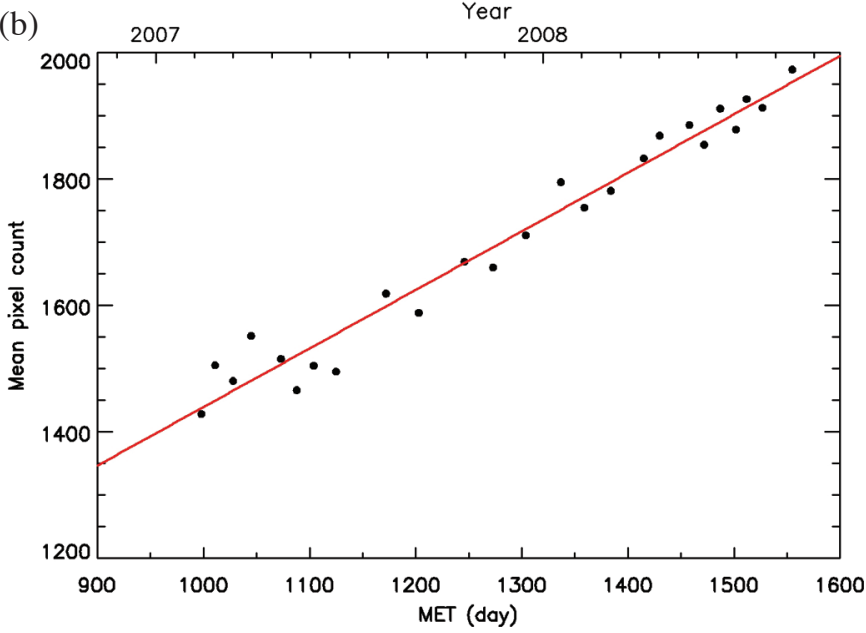

Fig. 6. (a) Background changes for the short exposure time $(30 \mathrm{~ms})$, data taken in the Southern (green filled circle) and Northern (blue filled circle) hemispheres are represented respectively. The brightness of phosphor still increased even after being on for 20 minutes and causes a systematic difference between the backgrounds taken at two hemispheres. (b) Background increase for long exposure time (1000 ms).

Table 4. Current and ceiling voltages applied to the electron multiplying devices. According to in-lab calibration data; an additional gain of at least a factor of 4 is still available.

\begin{tabular}{cccc}
\hline Sensor & Current voltage & Ceiling voltage & Available gain \\
\hline Imager (MCP) & $525 \mathrm{~V}$ (TLE obs.) & $\sim 900 \mathrm{~V}$ & \\
SP (SP2) & $1490 \mathrm{~V}$ & $\sim 2200 \mathrm{~V}$ & $>4 \mathrm{X}$ \\
AP & Low $(540 \mathrm{~V})$ & High $(860 \mathrm{~V})$ & \\
\hline
\end{tabular}


gain to compensate for this degradation. However without knowing the detailed spectra of different TLE types, the TLE energy distribution, and their occurrence rate, it would be difficult to quantitatively determine the impact of the gain adjustments.

To evaluate the impact of the high-voltage adjustments, three occurrence rates are carefully examined: the trigger rate which is defined as the number of all recorded ISUAL events including lightning, TLEs, and other possible cosmic-ray triggered events, divided by the observation time that was inferred from the ISUAL status of health data. The ISUAL lightning and TLE detection rates are formulated similarly and are the numbers of lightning and TLE events normalized to the observation time, respectively. The daily variations of these rates are displayed in Fig. 7, and the dates of both high-voltage adjustments (red dashed lines) and long-term averages (blue dashed lines) are also marked for easy reference. The annual variation patterns are obtained (blue solid lines) by smoothing the 5-year-averaged detection rates for the same annual phase or day of the year. The annual patterns for the ISUAL lightning and the ISUAL trigger rates are the results of the shift in the
ISUAL ground coverage and the migration of Earth's active lightning zones. From the previous lightning global survey (Christian et al. 2003), the occurrence density ratio of land and ocean lightning is known to be $\sim 10: 1$. Thus the global lightning rate is lowest during the summer of the Southern hemisphere, partly due to where the ratio of ocean to land is relatively high. Nevertheless, the annual lightning rate patterns during the ISUAL survey period are all very similar and show no discernible trend. Therefore, it is a good indication that the adjustments of ISUAL sensors' voltages have adequately compensated the lost of sensitivity due to the sensor degradation.

The most frequently occurring type of TLEs are elves $(\sim 80 \%)$ and their land-to-ocean occurrence ratio is reported to be $1: 1$ (Chen et al. 2009), therefore, the annual pattern of TLE rate is not very clearly distinguishable, except for the years 2008 and 2009. The elve occurrence rate is known to correlate strongly with the sea surface temperature (Chen et al. 2008) and the thermocline in the Pacific Ocean during the La Niña and El Niño events. The anomaly in the elve occurrence is expected to be discernible during La Niña or El Niño events. Therefore, the distinct annual pattern of TLE (a)
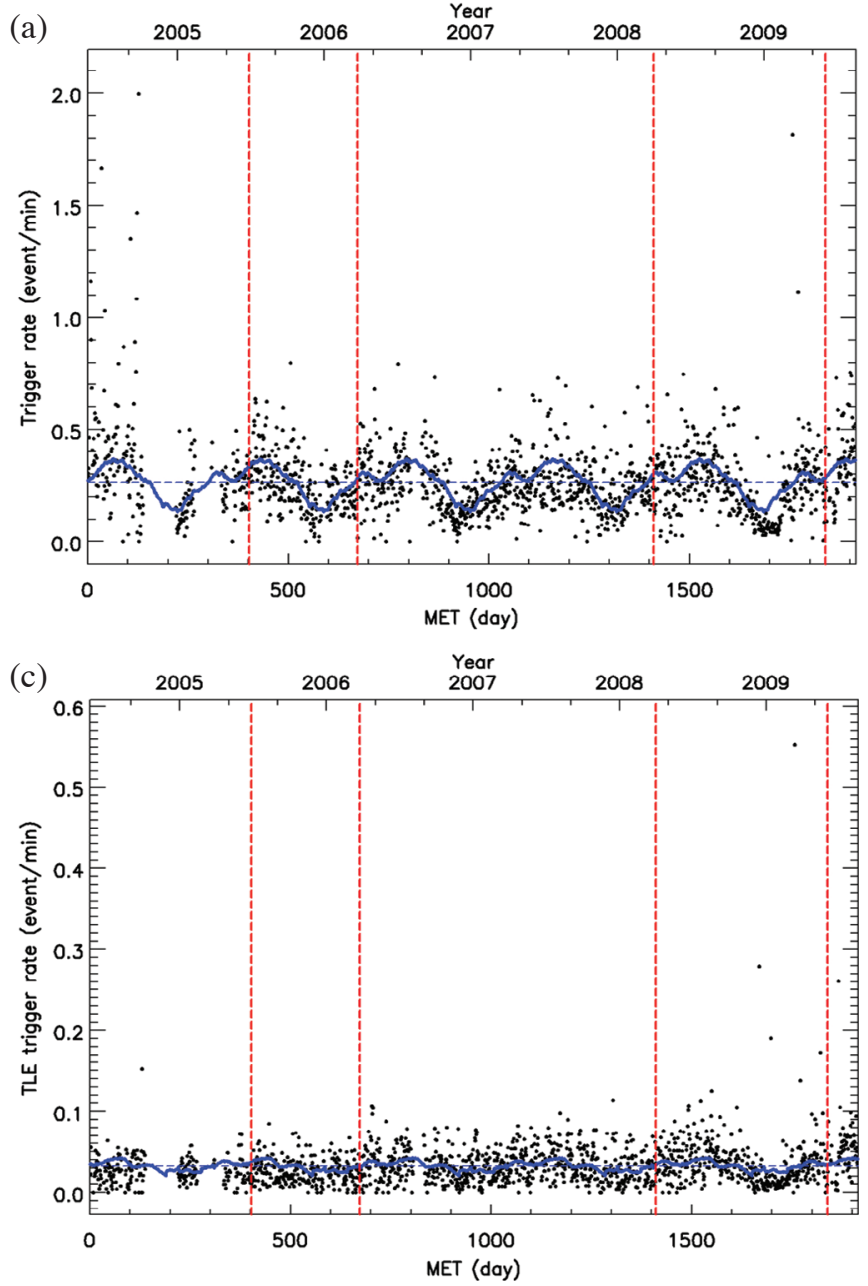

(b)

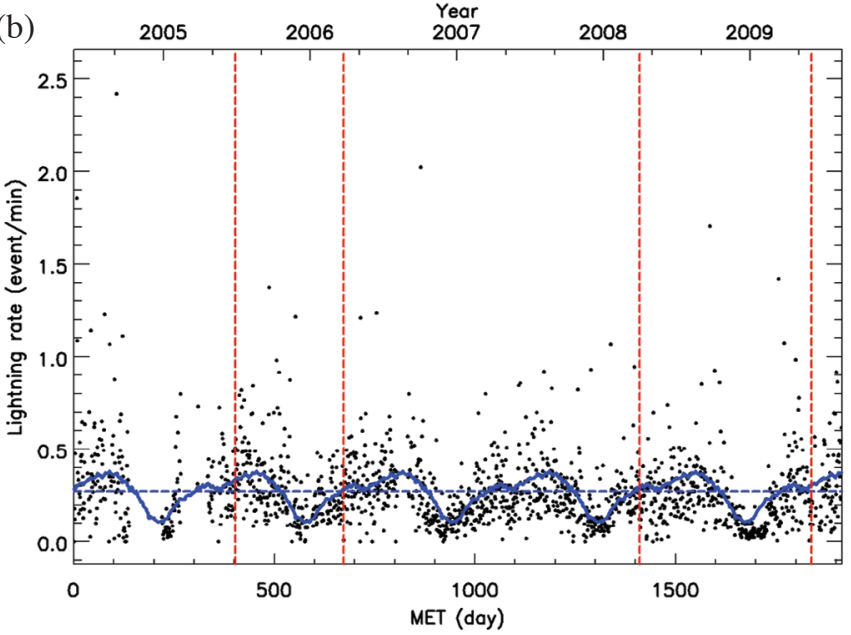

Fig. 7. Daily variation of the trigger (a), lightning (b), and TLE rates (c) from mission start to the end of 2009. The dashed red lines indicate the date of SP high-voltage adjustment, and the blue dashed lines mark the averages of the statistical duration. The annual variation patterns (blue solid lines) are derived by smoothing the 5 -year-averaged detection rates for the same day of the year. 
rate in $2008 \sim 2009$ is most likely due to the La Niña event not the gain adjustment. The correlation between the TLE occurrence during the La Niña and the El Niño events will be discussed in a separate paper. If one excludes the TLE rate for the years 2008 and 2009, the varying amplitudes of all rates stay nearly constant, with no notable decreasing or increasing trend between 2004 and 2007 even after the high-voltage adjustments. The above observational facts indicate that the degradation in the sensitivity of the sensors was properly compensated by the gain adjustment during the mission.

One may expect that the ISUAL event detection rates would be elevated immediately right after the increase of the high voltage supplied. Unfortunately, the day-to-day variation and the seasonal changes are more notable than the effect of the increase in the effective gain. For example, the third and fourth adjustment occurred in the declining phase of an annual cycle and the detected rate kept the decreasing trend after increasing the supplied voltage. We also noticed that, for some instances, the ISUAL detection rates increased suddenly for one or a few adjacent days. After careful inspection, such rates were often due to ISUAL passing over long lasting, active thunderstorms. We also expect that background noise will be elevated when the sky background is brighter, so the false triggers caused by the noise would be increased during a full moon. Considering these factors with vast time scale differences, from a day to a season, hence it is very difficult to identify the significance and the confidence level of rate changes whether were from the change in SP high-voltage supply.

We further calculate the global occurrence rate, land-toocean ratio, and the percentage of major TLE types (sprites, elves, halos and gigantic jets) between July 2004 and August 2010 using the method discussed in Chen et al. (2008). A comparison of the these quantities with the results in Chen et al. (2008), and Hsu et al. (2009) is given in Table 5. The most current occurrence densities of TLEs are shown in Fig. 8. We found that the occurrence rates of sprites and halos stay nearly constant for different statistical intervals, but a growing trend of the elve occurrence rate is evident. The steady sprite and halo occurrence rates imply that the increase in the elve occurrence rate probably is not due to a change in the sensor performance. A detailed inspection of the Elves occurrence density anomaly in $2008 \sim 2009$ further suggests that this variation likely was caused by the occurrence of El Niño and Southern Oscillation (ENSO) (Wu et al. 2010).

All in all, the stable ISUAL trigger and lightning events suggest that the bias due to instrument degradation and the gain adjustment has been minimized empirically and successfully. This result implies that no additional correction for the variation of detection capability is needed for the statistical analyses of the TLE global occurrence rate and distribution reported by Chen et al. (2008), Lee et al. (2010), as well as the studies of the ISUAL recorded lightning (Chen et al. 2007; Wu et al. 2010).

\section{CONCLUSION}

Since 2004, the ISUAL apparatus on-board the FORMOSAT-2 has carried out a global survey of TLE for more than 6 years. To maintain a high quality survey mission, the photon-sensing photomultipliers, multi-anode array, and the micro-channel plate have to be continuously maintained and calibrated. These sensors provide data for the identification of transient events and they must sustain a prolonged mission that operates more than 5 hours per day/300 days per year in a demanding space environment (Chen et al. 2009). The low-light event sensing devices of ISUAL, however, will degrade gradually with age. Indeed, annual degradation rates were found to be uneven among the sensor elements and can be up to $14 \%$ for some of the units. Hence to achieve precise photometry (Kuo et al. 2005) and accurate statistics (Chen et al. 2008; Lee et al. 2010), performances of the lowlight devices have to be monitored and supplying voltages have to be adjusted to compensate for the degradation.

In this paper, we present long-term variations of the ISUAL trigger, lightning, and TLE detection rates between 2004 and 2010. Detailed analyses indicate that, even with four high voltage increases during this period, no notable increasing or decreasing trends was revealed in the ISUAL trigger and lightning detection rates. While the detection rates of sprites and halos stay nearly uniform for different statistical intervals, the elve occurrence rate showed a significant increase during $2008 \sim 2009$, which was likely due to the occurrence of El Niño and Southern Oscillation

Table 5. Comparison of the results given in Chen et al. (2008) (C08), Hsu et al. (2009) (H09), and this work (C10). Columns from left to right for each work: Number, type percentage of TLEs, land-to-ocean ratio (L\&C:O), and the raw TLE occurrence rate (unit: events/minute).

\begin{tabular}{|c|c|c|c|c|c|c|c|c|c|c|c|c|}
\hline \multirow{2}{*}{$\begin{array}{c}\begin{array}{c}\text { Reference } \\
\text { (Data interval) }\end{array} \\
\text { ELVEs }\end{array}$} & \multicolumn{4}{|c|}{$\begin{array}{c}\mathrm{C} 08 \\
(2004 / 07 \text { to 2007/06) }\end{array}$} & \multicolumn{4}{|c|}{$\begin{array}{c}\text { H09 } \\
(2004 / 07 \text { to 2008/06) }\end{array}$} & \multicolumn{4}{|c|}{$\begin{array}{c}\text { C10 } \\
(2004 / 07 \text { to 2010/08) }\end{array}$} \\
\hline & 5434 & $80.7 \%$ & $1.1: 1$ & 3.23 & 7964 & $82.5 \%$ & $1.1: 1$ & 3.62 & 14429 & $84.3 \%$ & $1.2: 1$ & 3.97 \\
\hline Sprites & 633 & $9.4 \%$ & $4.1: 1$ & 0.50 & 826 & $8.6 \%$ & $4.1: 1$ & 0.47 & 1340 & $7.8 \%$ & $3.6: 1$ & 0.46 \\
\hline Halos & 657 & $9.8 \%$ & $2.4: 1$ & 0.39 & 842 & $8.7 \%$ & $2.5: 1$ & 0.37 & 1285 & $7.5 \%$ & $2.5: 1$ & 0.35 \\
\hline Gigantic Jets & 13 & $0.2 \%$ & $0.7: 1$ & $<0.01$ & 19 & $0.2 \%$ & $1.1: 1$ & na & 60 & $0.4 \%$ & $2.1: 1$ & $<0.01$ \\
\hline
\end{tabular}


(a) sprites

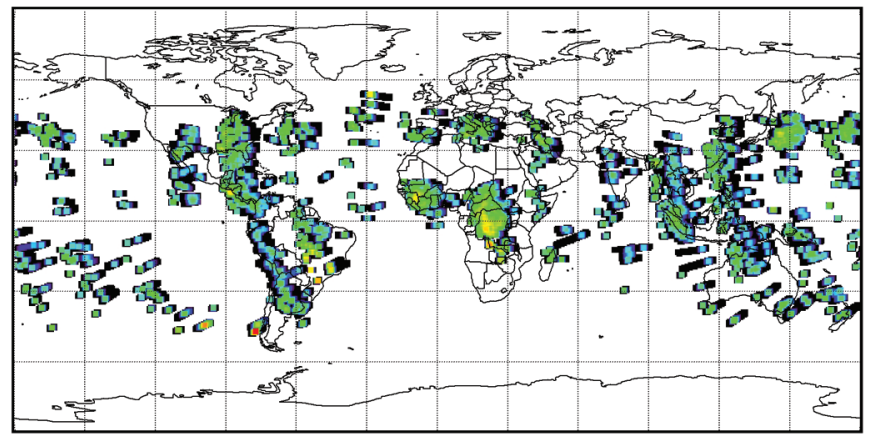

(c) halos

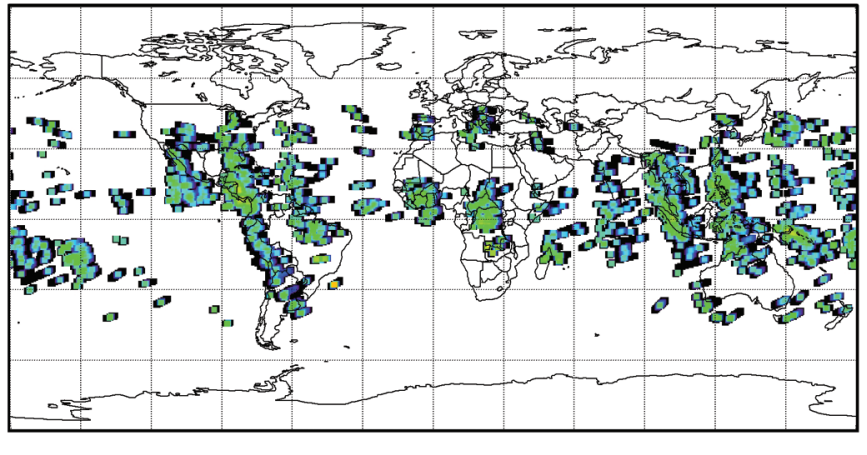

(b) elves

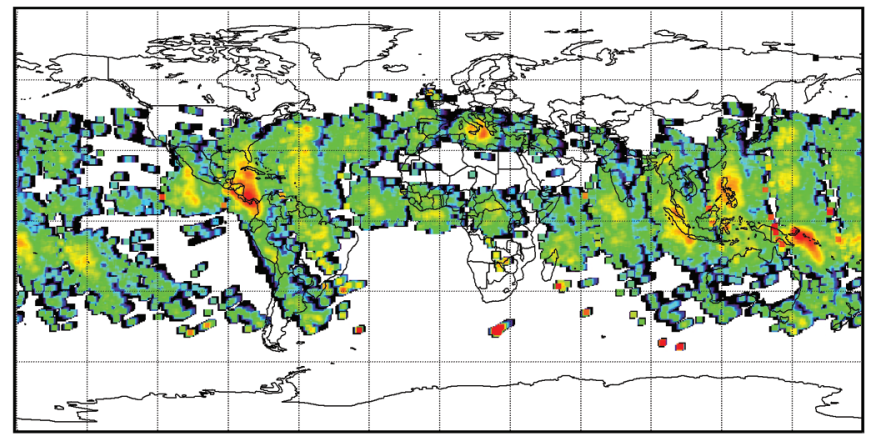

(d) gigantic jets

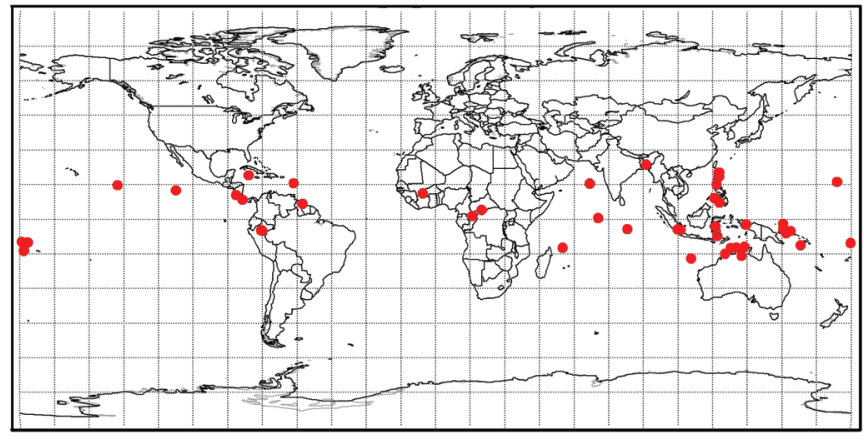

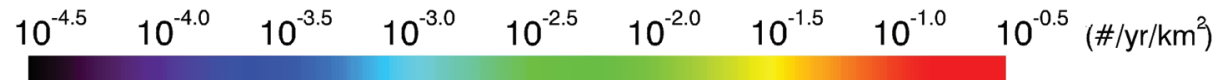

Fig. 8. The global occurrence density of major TLEs: sprites (a), elves (b), halos (c) and gigantic jets (d) (due to the low occurrence, the red-filled circles denote the occurrence of GJs insead of the occurrence density). This statistic is derived from the ISUAL observations between July 2004 and August 2010.

(ENSO) events. By comparing the global TLE distributions shown in Fig. 8 and the corresponding graphs in Chen et al. (2008) (Fig. 3), it can be found that elve occurrence became more active above around the central Pacific Ocean during $2008 \sim 2009$ (Wu et al. 2010). Since the effective detection capability of ISUAL has been demonstrated to be wellmaintained through proper adjustments of the sensor high voltages, therefore the anomalies found in the global TLE detection rates likely can be attributed to the climate events and studied accordingly.

The quantitative analyses presented in this work also suggest that ISUAL will be able to operate at least until the end of 2013, provided no hardware failure takes place. Several new space missions with the TLE research being the primary focus, for example, TARANIS (Blanc et al. 2007) and ASIM (Neubert et al.2006), will be launched some time after 2011. The extended ISUAL mission can continue its global survey of TLEs until the follow-up missions begin to take over. These long-term global monitoring TLE missions can provide helpful data that will enable us to better understand the correlation between the atmospheric electricity and the short-term climate events such as El Niño and La Niña, and to some degree, the effects of the solar cycle on the atmospheric electricity.
Acknowledgments This work was supported in part from the National Space Organization (NSPO) and National Science Council in Taiwan under grant number: NSPOS-100010, NSC 100-2111-M-006-002, NSC97-2111M-006-004-MY3, NSC 97-2111-M-006-001-MY3 and NSC99-2112-M-006-006-MY3. Thanks are due to Drs. T. Y. Liu and S. F. Lin for operation supports.

\section{REFERENCES}

Adachi, T., H. Fukunishi, Y. Takahashi, Y. Hiraki, R. R. Hsu, H. T. Su, A. B. Chen, S. B. Mende, H. U. Frey, and L. C. Lee, 2006: Electric field transition between the diffuse and streamer regions of sprites estimated from ISUAL/array photometer measurements. Geophys. Res. Lett., 33, L17803, doi: 10.1029/2006GL026495. [Link]

Adachi, T., Y. Hiraki, K. Yamamoto, Y. Takahashi, H. Fukunishi, R. R. Hsu, H. T. Su, A. B. Chen, S. B. Mende, H. U. Frey, and L. C. Lee, 2008: Electric fields and electron energies in sprites and temporal evolutions of lightning charge moment. J. Phys. D: Appl. Phys., 41, 234010, doi: 10.1088/0022-3727/41/23/234010. [Link] 
Blanc, E., T. Farges, R. Roche, D. Brebion, T. Hua, A. Labarthe, and V. Melnikov, 2004: Nadir observations of sprites from the International Space Station. J. Geophys. Res., 109, A02306, doi: 10.1029/2003JA009972. [Link]

Blanc, E., F. Lefeuvre, R. Roussel-Dupré, and J. A. Sauvaud, 2007: TARANIS: A microsatellite project dedicated to the study of impulsive transfers of energy between the Earth atmosphere, the ionosphere, and the magnetosphere. Adv. Space Res., 40, 1268-1275, doi: 10.1016/j.asr.2007.06.037. [Link]

Boccippio, D. J., W. J. Koshak, and R. J. Blakeslee, 2002: Performance assessment of the Optical Transient Detector and Lightning Imaging Sensor. Part I: Predicted diurnal variability. J. Atmos. Ocean. Technol., 19, 1318-1332, doi: 10.1175/1520-0426(2002)019<1318: PAOTOT>2.0.CO;2. [Link]

Boeck, W. L., O. H. Vaughan Jr., R. J. Blakeslee, B. Vonnegut, M. Brook, and J. McKune, 1995: Observations of lightning in the stratosphere. J. Geophys. Res., 100, 1465-1475, doi: 10.1029/94JD02432. [Link]

Boeck, W. L., O. H. Vaughan Jr., R. J. Blakeslee, B. Vonnegut, and M. Brook, 1998: The role of the space shuttle videotapes in the discovery of sprites, jets and elves. J. Atmos. Sol.-Terr. Phys., 60, 669-677, doi: 10.1016/ S1364-6826(98)00025-X. [Link]

Chen, A. B., C. Y. Chiang, C. T. Su, Y. J. Lee, C. P. Hu, L. Y. Tsai, Y. C. Huang, J. K. Chou, L. J. Lee, S. M. Huang, R. R. Hsu, H. T. Su, T. Y. Liu, Y. S. Chang, and L. C. Lee, 2007: Distribution and seasonal variation of global lightning activities observed by ISUAL experiment, American Geophysical Union, Fall Meeting 2007, abstract \#AE23A-0888.

Chen, A. B., C. L. Kuo, Y. J. Lee, H. T. Su, R. R. Hsu, J. L. Chern, H. U. Frey, S. B. Mende, Y. Takahashi, H. Fukunishi, Y. S. Chang, T. Y. Liu, and L. C. Lee, 2008: Global distributions and occurrence rates of transient luminous events. J. Geophys. Res., 113, A08306, doi: 10.1029/2008JA013101. [Link]

Chen, A. B., C. Y. Chiang, Y. C. Huang, and Y. J. Wu, 2009: Current status of the ISUAL instruments and a forecast to the extension mission, ISUAL 2009 Conference, Tainan, Taiwan.

Chern, J. L., R. R. Hsu, H. T. Su, S. B. Mende, H. Fukunishi, Y. Takahashi, and L. C. Lee, 2003: Global survey of upper atmospheric transient luminous events on the ROCSAT-2 satellite. J. Atmos. Sol.-Terr. Phys., 65, 647-659, doi: 10.1016/S1364-6826(02)00317-6. [Link]

Christian, H. J., R. J. Blakeslee, D. J. Boccippio, W. L. Boeck, D. E. Buechler, K. T. Driscoll, S. J. Goodman, J. M. Hall, W. J. Koshak, D. M. Mach, and M. F. Stewart, 2003: Global frequency and distribution of lightning as observed from space by the Optical Transient Detector.
J. Geophys. Res., 108, doi: 10.1029/2002JD002347. [Link]

Cummer, S. A., 2006: Measurements of lightning parameters from remote electromagnetic fields, Proceedings of the NATO Advanced Study Institute on "Sprites, Elves and Intense Lightning Discharges," Corte, Corsica, France 24-31 July 2004.

Franz, R. C., R. J. Nemzek, and J. R. Winckler, 1990: Television image of a large upward electrical discharge above a thunderstorm system. Science, 249, 48-51, doi: 10.1126/science.249.4964.48. [Link]

Frey, H. U., S. B. Mende, S. A. Cummer, A. B. Chen, R. R. Hsu, H. T. Su, Y. S. Chang, T. Adachi, H. Fukunishi, and Y. Takahashi, 2005: Beta-type stepped leader of elve-producing lightning. Geophys. Res. Lett., 32, L13824, doi: 10.1029/2005GL023080. [Link]

Fukunishi, H., Y. Takahashi, M. Kubota, K. Sakanoi, U. S. Inan, and W. A. Lyons, 1996: Elves: Lightning-induced transient luminous events in the lower ionosphere. Geophys. Res. Lett., 23, 2157-2160, doi: 10.1029/96G L01979. [Link]

Huang, E., E. Williams, R. Boldi, S. Heckman, W. Lyons, M. Taylor, T. Nelson, and C. Wong, 1999: Criteria for sprites and elves based on Schumann resonance observations. J. Geophys. Res., 104, 16943-16964, doi: 10. 1029/1999JD900139. [Link]

Huang, T. Y., C. L. Kuo, C. Y. Chiang, A. B. Chen, H. T. Su, and R. R. Hsu, 2010: Further investigations of lightning-induced transient emissions in the $\mathrm{OH}$ airglow layer. J. Geophys. Res., 115, A10326, doi: 10.1029/2010JA015558. [Link]

International Organization for Standardization, 2010: Space systems - Space environment - Simulation guidelines for radiation exposure of non-metallic materials, ISO 15856:2010.

Kuo, C. L., R. R. Hsu, A. B. Chen, H. T. Su, L. C. Lee, S. B. Mende, H. U. Frey, H. Fukunishi, and Y. Takahashi, 2005: Electric fields and electron energies inferred from the ISUAL recorded sprites. Geophys. Res. Lett., 32, L19103, doi: 10.1029/2005GL023389. [Link]

Kuo, C. L., A. B. Chen, Y. J. Lee, L. Y. Tsai, R. K. Chou, R. R. Hsu, H. T. Su, L C. Lee, S. A. Cummer, H. U. Frey, S. B. Mende, Y. Takahashi, and H. Fukunishi, 2007: Modeling elves observed by FORMOSAT-2 satellite. J. Geophys. Res., 112, A11312, doi: 10.1029/ 2007JA012407. [Link]

Kuo, C. L., J. K. Chou, L. Y. Tsai, A. B. Chen, H. T. Su, R. R. Hsu, S. A. Cummer, H. U. Frey, S. B. Mende, Y. Takahashi, and L. C. Lee, 2009: Discharge processes, electric field, and electron energy in ISUAL-recorded gigantic jets. J. Geophys. Res., 114, A04314, doi: 10. 1029/2008JA013791. [Link]

Lee, L. J., A. B. Chen, S. C. Chang, C. L. Kuo, H. T. Su, R. 
R. Hsu, C. C. Wu, P. H. Lin, H. U. Frey, S. B. Mende, Y. Takahashi, and L. C. Lee, 2010: Controlling synoptic-scale factors for the distribution of transient luminous events. J. Geophys. Res., 115, A00E54, doi: 10.1029/2009JA014823. [Link]

Lischka, H., P. Clemens, H. Henschel, O. Köhn, W. Lennartz, and H. U. Schmidt, 1994: Radiation effects in optoelectronic devices, SPIE Proceedings Series 2425, 43-52.

Liu, N., V. P. Pasko, D. H. Burkhardt, H. U. Frey, S. B. Mende, H. T. Su, A. B. Chen, R. R. Hsu, L. C. Lee, H. Fukunishi, and Y. Takahashi, 2006: Comparison of results from sprite streamer modeling with spectrophotometric measurements by ISUAL instrument on FORMOSAT-2 satellite. Geophys. Res. Lett., 33, L01101, doi: 10.1029/2005GL024243. [Link]

Mach, D. M., H. J. Christian, R. J. Blakeslee, D. J. Boccippio, S. J. Goodman, and W. L. Boeck, 2007: Performance assessment of the Optical Transient Detector and Lightning Imaging Sensor. J. Geophys. Res., 112, D09210, doi: 10.1029/2006JD007787. [Link]

Massey, R., 2010: Charge transfer inefficiency in the Hubble Space Telescope since Servicing Mission 4. Mon. Not. R. Astron. Soc., 409, L109-L113, doi: 10.1111/j.17453933.2010.00959.x. [Link]

Mende, S. B., H. U. Frey, R. R. Hsu, H. T. Su, A. B. Chen, L. C. Lee, D. D. Sentman, Y. Takahashi, and H. Fukunishi, 2005: $D$ region ionization by lightning-induced electromagnetic pulses. J. Geophys. Res., 110, A11312, doi: 10.1029/2005JA011064. [Link]

Neubert, T., I. Kuvvetli, C. Budtz-Jørgensen, N. Østgaard, V. Reglero, and N. Arnold, 2006: The AtmosphereSpace Interactions Monitor (ASIM) for the Interna- tional Space Station, Proceedings of the ILWS Workshop, Goa, India, February 19-24, 2006.

Rajesh, P. K., J. Y. Liu, C. Y. Chiang, A. B. Chen, W. S. Chen, H. T. Su, R. R. Hsu, C. H. Lin, M. L. Hsu, J. H. Yee, and J. B. Nee, 2009: First results of the limb imaging of $630.0 \mathrm{~nm}$ airglow using FORMOSAT-2/Imager of Sprites and Upper Atmospheric Lightnings. J. Geophys. Res., 114, A10302, doi: 10.1029/2009JA014087. [Link]

Sato, M. and H. Fukunishi, 2003: Global sprite occurrence locations and rates derived from triangulation of transient Schumann resonance events. Geophys. Res. Lett., 30, 1859, doi: 10.1029/2003GL017291. [Link]

Schubert, E. F., 2006: Light-Emitting Diodes, Cambridge University Press, Cambridge, UK, 432 pp.

Walker, T. E., D. R. Smith, C. J. Howe, B. J. Kellett, P. Sreekumar, and M. Grande, 2010: The effects of radiation damage on the spectral resolution of the Chandrayaan-1 x-ray spectrometer, High Energy, Optical, and Infrared Detectors for Astronomy IV, Proc. SPIE 7742, San Diego, California, USA, Sunday 27 June 2010, doi: 10.1117/12.858648. [Link]

Wu, Y., A. B. Chen, J. Chou, S. Chang, L. Lee, Y. Lee, C. Kuo, H. Su, R. Hsu, H. U. Frey, S. B. Mende, Y. Takahashi, and L. C. Lee, 2010: Occurrence of Transient Luminous Event and Lightning during El Niño and La Niña, American Geophysical Union, Fall Meeting 2010, abstract \#AE21B-0282.

Yair, Y., P. Israelevich, A. D. Devir, M. Moalem, C. Price, J. H. Joseph, Z. Levin, B. Ziv, A. Sternlieb, and A. Teller, 2004: New observations of sprites from the space shuttle. J. Geophys. Res., 109, D15201, doi: 10. 1029/2003JD004497. [Link] 